\title{
Pós-modernismo, descentramento do sujeito e mapeamento cognitivo em Fredric Jameson
}

\author{
Postmodernism, decentering of the subject and cognitive mapping in Fredric Jameson \\ Postmodernismo, descentramiento del sujeto y mapeo cognitivo en Fredric Jameson \\ Wibsson Ribeiro Lopes $\odot$ \\ Universidade Estadual de Campinas (UNICAMP), Campinas, SP, Brasil.
}

\begin{abstract}
RESUMO
Este artigo pretende apresentar o diagnóstico do pós-modernismo construído por Fredric Jameson em sua obra, com atenção especial para a questão do descentramento do sujeito e da necessidade de se construir um mapeamento cognitivo para situar o sujeito na vida dentro do capitalismo, que agora aparece para a humanidade como uma segunda natureza. Como demonstração de uma tentativa de representar esta totalidade, apresentamos a visão de Jameson a respeito do Cyberpunk e do romance Neuromancer, de William Gibson. O objetivo é apresentar uma forma de crítica e de produção literária que fornece elementos tanto pedagógicos quanto formais para pensar o contemporâneo.
\end{abstract}

Palavras-chave: Pós-modernismo. Mapeamento Cognitivo. Fredric Jameson. Cyberpunk.

\section{ABSTRACT}

This paper intend to present the diagnose of the postmodernism built by Fredric Jameson in your work, with close attention to te question of the decentering of the subject and the necessity to built a cognitive mapping to position the subject in the life inside the capitalism, which now shows itself to the humanity like a second nature. To demonstrate a tentative to represent this totality, we present the vision of Jameson about the cyberpunk gender and the novel Neuromancer, from William Gibson. The Objective is to present a form of literary criticism and production with formal and also pedagogical elements to think the contemporary.

Keywords: Postmodernism. Cognitive Mapping. Fredric Jameson. Cyberpunk.

\section{RESUMEN}

Este artículo pretende presentar el diagnóstico del postmodernismo construido por Fredric Jameson en su obra, con atención especial a la cuestión del descentramiento del sujeto y de la necesidad de construir un mapeo cognitivo para situar el sujeto en la vida dentro del capitalismo, que ahora aparece para la humanidad como una segunda naturaleza. Como demonstración de una tentativa de representar esta totalidad, presentamos la visión de Jameson con respecto al Cyberpunk y al romance Neuromancer, de William Gibson. El objetivo es presentar una forma de crítica y de producción literaria que proporciona elementos tanto pedagógicos como formales para pensar el contemporáneo.

Palabras clave: Postmodernismo. Mapeo Cognitivo. Fredric Jameson. Cyberpunk. 


\section{Introdução}

A palavra pós-modernismo se desgastou rapidamente, tornou-se um jargão e, para alguns, na pior das hipóteses, deveria ser abandonada. Leyla Perrone-Moisés, uma das nossas maiores críticas, desdenha, com certa razão, das definições correntes, lembrando que desde os primórdios do Romance, com Dom Quixote de Cervantes, até o Tristam Shady de Sterne, outro clássico do gênero, o pastiche, a paródia, as referências a outros textos, as digressões e tantas outras características basilares do dito pós-modernismo já eram comuns (PERRONE-MOISÉS, 2015). No entanto, pensamos que há algo a ser conservado tema, que representou ao menos um momento importante do debate teórico dos anos 1970 até os dias atuais. Aliás, hoje vemos um retorno do termo por parte principalmente de intelectuais conservadores, que o brandem como uma acusação quase moral contra seus opositores.

Nesse artigo buscamos resgatar as reflexões sobre o pós-modernismo e a pós-modernidade elaboradas por um de seus mais argutos pesquisadores, o crítico cultural Fredric Jameson. A partir dele iremos pensar a questão do descentramento do sujeito na contemporaneidade e a proposta de um mapeamento cognitivo para se situar na incomensurabilidade do mundo contemporâneo.

\section{Pensar o pós-modernismo}

Indo direto ao ponto, e recorrendo ao subtítulo de um dos mais célebres livros do autor, para Jameson o pós-modernismo nada mais é do que a lógica cultural do capitalismo tardio (1997b). O autor busca com seu método estabelecer uma relação entre formas culturais e a realidade específica do modo de produção capitalista, investigando quais seriam as expressões artísticas predominantes, mas não exclusivas, de cada período.

Se a Revolução Francesa e a Revolução Americana abriram o caminho para a emergência do Romance Histórico, como os inaugurados por Walter Scott, isto é, da história percebida como possível de sofrer a intervenção da humanidade, o Realismo seria a forma do capitalismo clássico, aquele em vias de consolidação na Europa. A este momento se seguiria o Imperialismo, a era da rapina dos continentes da Ásia, da Oceania, da África e da América pelas potências da Europa.

Ele é definido por Lênin como a "Etapa superior do capitalismo", época de fusão do Capital Industrial com o Bancário, fazendo emergir o Capital Financeiro. A lógica cultural do imperialismo teria sido marcada pelo Modernismo e as diversas vanguardas, que absorviam a influência das diversas artes e culturas do mundo e explodiam as bases do romance clássico, marcado por noções cartesianas de sujeito e percepção do tempo.
No modernismo, as convenções de tempo e espaço são desafiadas; predomina a multiplicidade de posições; as sensações e as experiências do sujeito comum são elevadas a uma dignidade nunca antes concebida; o interior psicológico das personagens é percorrido como um labirinto profundo. São romances como os de Virginia Wolf, o Ulysses e o Finnegans Wake de James Joyce, O som e a fúria de William Faulkner, para ficar apenas em alguns exemplos literários e apenas fazer menção ao expressionismo, ao dadaísmo, ao surrealismo, ao cubismo e a tantos outros movimentos revolucionários na arte e na cultura que emergiram no período que servem de maior significação para esta fase.

Jameson observa como nas obras literárias surge a percepção de que há um sistema colonial maior do que os indivíduos, mas os sujeitos estão restritos à sua própria experiência, a seu espaço de vivência. O modernismo joga com o presente e o ausente, com "formas que inscrevem um novo sentido do sistema colonial global ausente na própria sintaxe da linguagem poética" (JAMESON, 1997b, p. 407). Também relativo ao período, é no final do século XIX que começa a surgir o que Jameson chama de "relativismo monádico". Em autores como Pessoa, Gide, Conrad, Henry James, Proust e outros,

começamos a ver o sentido de que cada consciência é um mundo fechado, de tal forma que a representação da totalidade social tem agora que assumir a forma impossível de uma coexistência desses mundos subjetivos selados, que é na verdade um passar de navios no meio da noite, um movimento centrífugo de linhas e planos que não podem nunca se intersectar (JAMESON, 1997b, p.407). .

É a época da predominância da figura de linguagem da ironia (Idem, 407). e da experiência de uma classe média urbana que vive essa "estranha nova relatividade global do sistema colonial" (Idem, 408).

Se isso é verdade para o modernismo, o pósmodernismo vem a exacerbar esta condição. Ele, portanto, seria a lógica cultural de uma época de transformações no capitalismo ocorridas a partir da década de 1970, ao menos, mas com sinais de mudança sendo perceptíveis já desde a década de 1950: o predomínio absoluto do capital financeiro; o desemprego estrutural; a entrada em cena de novas tecnologias da informação e de um predomínio midiático sobre as relações individuais; o estabelecimento de uma situação que poderíamos definir como neoliberal nas políticas de governo e diretrizes econômicas de governos centrais do capitalismo, especialmente com Ronald Reagan nos Estados Unidos e Margareth Tatcher na Inglaterra.

O pós-modernismo é também o resultado de uma absorção. Todas as vanguardas modernistas eram vistas 
como transgressoras, outsiders. Agora elas entram no museu, são integradas ao establishment artístico. Perdem a sua aura de confrontação ao capitalismo liberal e tornam-se artefatos culturais livremente manuseáveis. São canonizadas.

As velhas vanguardas dão lugar a figura do curador, daquele que agrupa diversos objetos de arte, do organizador dos museus, do produtor, do teórico que monta um pensamento a partir do agrupamento de distintos autores e filósofos. É aí que se consolida o que entendemos por pós-modernismo. Além disso, as estratégias usadas pelos modernistas para lidar com o sistema global hoje parecem insuficientes, inadequadas diante de um mundo marcado pelo "descentramento e pela dispersão esquizofrênica e fragmentada" (JAMESON,1997b, p. 408). do sujeito.

Para quem poderia torcer o nariz para uma periodização desse tipo, que em algum nível pode parecer excessivamente cronológica e esquemática, Jameson responderia que tal procedimento é da ordem do inevitável. "Sempre historicizar!", foi seu lema nos anos 1980 (JAMESON, 1992), e tal é condizente com sua atitude diante da história das formas artísticas.

Há muita desconfiança por parte do autor com a postura de abolir um senso de história e periodização. Jameson afirma que rejeitar isso apenas conduz a um retorno de um tipo de história ainda mais abominável, aquele tempo das crônicas dos reis e homens ilustres (JAMESON, 2005, p. 41-2), uma história elitista contra a qual batalhou durante o século XX, dentre outros, a Escola dos Annales e a historiografia marxista.

Portanto, Jameson segue com esta divisão do tempo no intuito de perceber as mudanças e transformações que acontecem na cultura, sem desvinculá-las de um contexto social, econômico e político mais amplo. Frise-se que é por isto que para o autor o pós-modernismo não deve ser visto como um "estilo", mas como uma dominante cultural, uma tendência predominante (JAMESON, 1997b, p. 29).

$\mathrm{Na}$ verdade, com o desaparecimento da noção de sujeito centrado, como receptor monádico, temos a crise dos estilos, das vanguardas. O pós-modernismo marca "o fim do ego burguês, ou da mônada (...). o fim das psicopatologias desse ego - (...). esmaecimento do afeto" (JAMESON, 1997b, p.43). Não só o esmaecimento do afeto:

Mas isso também implica o fim de muitas outras coisas, o fim da pincelada individual distinta (como simbolizado pela primazia emergente da reprodução mecânica). No que diz respeito a expressão e sentimentos ou emoções, a liberação de qualquer outro tipo de sentimento, uma vez que não há mais a presença de um ego para encarregar-se de sentir. Isso não é a mesma coisa que dizer que os produtos culturais da era pós-moderna são completamente destituídos de sentimentos, mas sim que tais sentimentos - a que pode ser melhor e mais correto chamar, seguindo Lyotard, de "intensidades"são agora auto-sustentados e impessoais e costumam ser dominados por um tipo peculiar de euforia (...). (JAMESON, 1997b, p. 43).

O tempo, ou a temporalidade, com isso, também se enfraquece como uma grande categoria articuladora dos sujeitos. Em seu lugar, vemos uma predominância maior do espaço. Os romances, que antes estabeleciam sua ação a partir de uma sucessão cronológica (mesmo romances radicais como o mencionado Ulysses de Joyce, ou Mrs. Dalloway, de Virgínia Wolf, por exemplo, que se passavam em um único dia), agora começam a se estabelecer de acordo com uma lógica espacial. As histórias se delineiam a partir das localizações e personagens de um prédio, como em A vida: modo de usar, de George Perec (1991).

Não é que o tempo é abolido como categoria central das obras de ficção, mas há como que um esmaecimento, um enfraquecimento deste enquanto o espaço assume uma força maior, por isso predominante. Uma outra forma de observar esse enfraquecimento do tempo é através do fortalecimento da nostalgia no cinema e na literatura, ou de uma relação fetichista com o tempo.

Dois exemplos do assunto são tirados das análises de Jameson. No romance Ragtime, de E.L. Doctorow (2017), somos apresentados a uma série de personagens, alguns deles misturados com figuras reais, como o mágico Houdini ou a anarquista Emma Goldman, em uma história que não é um romance de época, mas um encadeamento de clichês de época - protestos anarquistas violentos, greves gerais, o surgimento do cinema, conflitos raciais entre negros e brancos nos Estados Unidos, a moda da época, etc. - algo que nos parece incrivelmente familiar, mas ao mesmo tempo desconcertante, demasiadamente plano. Temos acesso não a um romance histórico, em suma, mas a um romance sobre as imagens que convencionamos ter do período.

Resultado semelhante, por procedimento diferente, pode ser encontrado no romance Time out of Joint, do escritor de ficção científica Philip K. Dick. Nele, o personagem central vive, sem o saber, em uma cidade americana artificial dos anos 1950. Aqui também o imaginário que se tem de uma década vivida com tanta euforia pelos estadunidenses, como uma época de prosperidade e bem-estar devido ao boom do pós-guerra, é entregue ao leitor. Não mais uma ficção histórica somente, mas uma obra de nostalgia histórica. Determinada década é reificada, congelada como mais um produto para consumo.

Saindo da esfera do romance e adentrando rapidamente na cultura de massas, podemos ver a tendência contemporânea de produções que lidam com a nostalgia e com imagens reificadas de uma determinada época ou país. 
A série Stranger Things (2015-), um dos carros chefes da plataforma de streaming Netflix, é ambientada nos anos 1980 e é constituída toda a partir de um somatório de referências aos filmes da época. São pôsteres, cartazes nas paredes, falas ditas pelos personagens, planos, monstros, elementos no plot, quadros que sempre invocam outras imagens da nossa memória. É toda uma série de estratégias que visa à constituição de um ganho afetivo do telespectador, libidinalmente comprometido com aquele passado seja por tê-lo vivido ou por fetichizá-lo como uma fase marcante da produção cultural estadunidense.

\section{Estética da singularidade}

Jameson vê na estética pós-modernista uma estética da singularidade (JAMESON, 2015, p. 107). A redução das temporalidades, ou a espacialização do tempo, leva a uma estética do presente, do singular. O futuro se esvanece e o passado torna-se um borrão, havendo apenas o agora, o instante imediato da imagem, do simulacro, dos happenings.

A singularidade é "um presente puro sem passado ou futuro" (Idem, 113). Resta apenas o corpo, único espaço ao qual nos encontramos reduzidos. A comparação para esta percepção temporal tem que ser buscada no mercado financeiro e na lógica do derivativo.

Ele cria espaços-tempo, não propõe exatamente um futuro, mas outros presentes, onde os investimentos frutificarão. O derivativo não está preso a uma mercadoria, mas pode passar de um investimento em um aparelho celular, até diretamente o minério que o constitui, ou outra mercadoria. Ele é volátil, imaterial (JAMESON, 2015, p. 20-22).

Assim como no mundo da arte contemporâneo, o derivativo só existe por uma quantidade limitada de tempo. É como a apresentação curta, que se inscreve no agora e se esvanece pouco tempo depois, uma estrutura que só se junta uma vez, ou um evento irrepetível no tempo (Idem, p. 23).

Tanto o espaço ganha proeminência sobre o tempo que as discussões sobre o pós-modernismo começam a se destacar a partir da arquitetura e do urbanismo. O primeiro autor a pensar em um mapeamento cognitivo, noção que exploraremos mais adiante, foi o urbanista Kevin Lynch.

E foi nos debates sobre a arquitetura que começou a se perceber uma superação da estética modernista e a percepção de que estilos arquitetônicos antigos se tornavam imagens como em um inventário, a ser utilizadas pelos arquitetos de acordo com seu gosto. Um dos grandes momentos de análise de Jameson da obra pós-modernismo é a crítica do Hotel Bonaventure. Nele se percebem as características chaves do pós-modernismo que estamos vendo aqui, como a falta de profundidade e a confusão da própria percepção do espaço; observando esse hotel, Jameson conclui que

essa última mutação do espaço - o hiperespaço pós-modernista - finalmente conseguiu ultrapassar a capacidade do corpo humano de se localizar, de organizar perceptivamente o espaço circundante e mapear cognitivamente sua posição em um mundo exterior mapeável. Pode-se sugerir agora que esse ponto de disjunção alarmante entre o corpo e o ambiente construído - que está para o choque inicial do modernismo assim como a velocidade da nave espacial está para a do automóvel - seja visto como um símbolo e um análogo daquele dilema ainda mais agudo que é o da incapacidade de nossas mentes, pelo menos no presente, de mapear a enorme rede global e multinacional de comunicação descentrada em que nos encontramos presos como sujeitos individuais (JAMESON, 1997b, p. 70-1).

Esse desnorteamento das coordenadas básicas de estruturação espaço-temporal do sujeito traz inclusive problemas políticos. Como estamos insistindo, as noções cartesianas são totalmente embaralhadas no pósmodernismo.

$\mathrm{Na}$ concepção pós-moderna, as identidades se tornaram uma questão de representação, noções como raça, gênero, classe e outras, são vistas, antes de tudo, como construções sociais (FLISFEDER, 2018, p. 21).

Para Matthew Flisfeder, isso pode ser entendido de duas formas. Primeiro, após a II Guerra Mundial, principalmente a partir dos anos 1960, assistimos à entrada em cena de novos agentes políticos. O feminismo, o movimento negro lutando por igualdade, o movimento LGBT, dentre inúmeros outros, passaram a reivindicar direitos e se inserir na sociedade democrática do pós-guerra, provocando também na esquerda uma desestabilização nas suas concepções, principalmente a ideia do proletariado como o sujeito revolucionário prioritário, que deveria estar à frente na luta contra o capitalismo.

Não queremos nos aprofundar nesse ponto, que julgamos ser baseado em inúmeros mal-entendidos, tampouco achamos que o proletariado como classe deixou de ser importante no capitalismo tardio, mas o fato é que a entrada em cena desses novos sujeitos sociais alterou profundamente o mundo (FLISFEDER, 2018, p. 22-3). Mas, não é só com esses chamados novos sujeitos da história que a subjetividade burguesa se vê desestabilizada. Ainda segundo Flisfeder, a própria visão de uma natureza humana é questionada (Idem, p.24). O pós-modernismo questiona os fundacionismos e essencialismos concernentes ao homem e à natureza.

Outra forma de entender o período pós-moderno é a partir de um olhar sobre a proliferação de significantes sem articulação maior com algum significante mestre. 
Sem um lastro maior, imperaria uma lógica esquizofrênica de relações: "A diferença relaciona" (JAMESON, 1997, p. 53), seria o grande bordão pós-modernista. Pinturas, livros, eletrodomésticos, filmes, cartas, aparatos tecnológicos, todos eles poderiam estar articulados, mas não mais com base em grandes eixos de identidade, como a nação, a história, o sujeito ou o comunismo. Há uma proliferação de significantes que não estão mais ligados diretamente a significados.

A partir daí, mesmo a visão de um sujeito e uma temporalidade centradas passam a ficar em questão: a experiência psicológica de uma história de vida, um tempo cronológico estruturado em passado-presente-futuro, tudo isso entra em questão e emerge uma concepção esquizofrênica de experiência "dos puros significantes materiais, ou, em outras palavras, a uma série de puros presentes, não relacionados no tempo" (Idem, p. 54). O presente é vivenciado pelos indivíduos de forma esmagadora, como uma euforia quase alucinatória e excessiva, uma proliferação de signos entre o insuportável e o inebriante (Idem, p.54).

Temos também no pós-modernismo um enfraquecimento da prática da paródia em detrimento do pastiche. Na paródia, ainda há um grau de desafio, de afronta que é também reverência ao objeto parodiado. Já no pastiche não, estamos diante de uma paródia "branca", uma mera repetição mecânica de estilos, como quem disseca um animal morto.

Lembremos que a época pós-moderna é também a época do questionamento da própria noção de autoria, como evidenciado no célebre debate conduzido por nomes como Roland Barthes e Michel Foucault. Isto nos serve como mais um exemplo da perda de credibilidade do sujeito como entendido em termos cartesianos. Mesmo o autor não está imune a este questionamento do período. O sujeito está morto, como foi proclamado pela teoria pós-estruturalista naquele momento.

Há outros exemplos e pontos explorados por Jameson para definir o pós-modernismo ao longo de sua obra, o resultado final é que esta é uma arte de uma época de indefinição, na qual a cultura virou uma segunda natureza (JAMESON, 1997b, p. 13). Viver nas grandes cidades da época pós-moderna é viver sem bússola, sem orientação. O mundo globalizado é impossível de ser apreendido pela mente humana, as grandes cidades e o grande fluxo de mercadorias ao longo dos continentes é da ordem do incomensurável.

Na verdade, o grande "momento de verdade" do pósmodernismo é justamente "esse novo e original espaço global, extraordinariamente desmoralizante e deprimente" (JAMESON, 1997, p. 75). O sujeito se vê sem meios de apreender o sistema capitalista e mesmo o seu lugar nele, vivendo de forma atomizada, desconexa:
O que foi denominado 'sublime' pós-moderno é apenas o momento em que esse conteúdo se tornou mais explícito, veio para mais perto da superfície da consciência como um novo tipo de espaço coerente mesmo que um certo disfarce figural, ou ocultamento, ainda esteja em operação, em especial na temática do high-tech em que o novo conteúdo espacial ainda é dramatizado e articulado. Assim, as características anteriores do pós-modernismo, acima enumeradas, podem agora ser vistas como aspectos parciais (embora constitutivos). do mesmo objeto espacial geral (JAMESON, 1997b, p. 75).

\section{Mapeamento Cognitivo}

Em um mundo como esse, mesmo a atuação política parece prejudicada: como alterar um mundo que sequer entendemos mais como funciona e do qual não temos nenhuma noção de seus limites, que nos espanta com sua grandeza sublime? Para completar este cenário, a condição pós-moderna, de acordo com um autor como Lyotard (2009), é marcada pela morte das meta-narrativas, visões teleológicas da história são amplamente questionadas.

O marxismo e o comunismo, com sua proposta de revolução redentora, terminou nos Gulags do Stalinismo; o liberalismo, com sua proposta de uma sociedade livre e justa, termina em Guerras Mundiais sangrentas e no campo de concentração; a psicanálise, com a proposta de libertar o sujeito das amarras do inconsciente, também não parece capaz de resolver os problemas que ela própria cria em sua prática clínica, e um longo etc. Em suma, a condição pós-moderna é de cinismo, de desconfiança com grandes projetos, de desdém pelo discurso humanista e todas as variações dele que se forjaram ao longo dos séculos.

Mas, para Jameson, de qualquer modo os sujeitos produzem narrativas para tentar lidas com a realidade do capitalismo das multinacionais. Um exemplo tosco é dado pelas teorias da conspiração, que crescem em popularidade desde os anos 1980. Narrativas que têm como base a paranoia são justamente uma tentativa de lidar com esta incomensurabilidade. Visões da história como uma grande conspiração executada por uma força a operar nos bastidores, seja ela uma seita, um partido, um grupo secreto, um partido ou um "Eles" misterioso começam a se tornar um padrão em obras de ficção e mesmo em discursos políticos (JAMESON, 1995). Escândalos políticos como o caso Watergate apenas reforçam a sensação de que o sistema opera de forma consciente, como um imenso cérebro conspirador, contra a população.

Narrativas de paranoia são precárias, simples em demasia, mas são uma tentativa de dar conta da totalidade em uma época em que isto se torna cada vez mais difícil (Idem). Longe de arrefecer, as teorias da conspiração parecem na nossa época ganhar cada vez mais força e elas 
são tentativas de mapear a totalidade, ainda que os sujeitos engajados nelas possam não ter plena consciência disto.

Em um mundo globalizado, onde as condições geográficas tornam-se tão importantes, Jameson busca atualizar a antiga noção marxista de consciência de classe com a ideia de mapeamento cognitivo. Ela consistiria em "permitir a representação situacional por parte do sujeito individual em relação àquela totalidade mais vasta $\mathrm{e}$ verdadeiramente irrepresentável que é o conjunto das estruturas da sociedade como um todo" (JAMESON, 1997b, p. 77).

Isto é, nada mais do que mapear a totalidade, buscar entender também a condição de opressão e exploração que se vive no capitalismo contemporâneo. A ficção desempenha um papel nesse sentido, podendo cumprir função pedagógica, como no auge do modernismo de autores como Brecht ou Eisenstein.

Livros, filmes ou outras formas artísticas poderiam ajudar a ontologizar o presente, fornecer elementos para entender a realidade, oferecer sementes de utopia em meio à reificação. É claro que, do ponto de vista da representação, um projeto de tal envergadura é impossível e só pode conduzir ao fracasso.

Como abarcar a totalidade do capitalismo? Representar a economia global, as relações de exploração em seu todo é algo de extrema dificuldade. Ainda assim, Jameson insistirá no engajamento neste fracasso, na perseguição deste objetivo como forma de nos situarmos social, cultural e politicamente no mundo, "de tal modo que nós possamos começar novamente a entender nosso posicionamento como sujeitos individuais e coletivos e recuperar nossa capacidade de agir e lutar, que está, hoje, neutralizada pela nossa confusão espacial e social" (JAMESON, 1997b, p. 79).

Não se deve deixar de registrar, porém, o ceticismo diante do pós-modernismo como arte política. Domesticadas em museus ou em programas televisivos, as obras de arte sucumbem à lógica do valor de troca e não parecem oferecer algum tipo de resistência à dominação. O crítico pode assumir o papel de buscar os traços de cultura em meio à barbárie, invertendo a célebre fórmula de Benjamin, procurar a utopia na reificação.

É possível pensar como esse mapeamento cognitivo pode se estruturar a partir de posições periféricas. Tomemos como exemplo o caso do texto que serviu de manifesto ao movimento cultural conhecido como manguebeat, emergindo de Recife e capitaneado pelos grupos musicais Chico Science \& Nação Zumbi e Mundo Livre S.A., dentre outros. O "manifesto dos caranguejos com cérebro" (G1, 2009), escrito por Fred 04, integrante do grupo Mundo Livre S.A., é diretamente inspirado na estética cyberpunk, como podemos ver a partir de parágrafos chave como:
Em meados de 91, começou a ser gerado e articulado em vários pontos da cidade um núcleo de pesquisa e produção de ideias pop. O objetivo era engendrar um *circuito energético*, capaz de conectar as boas vibrações dos mangues com a rede mundial de circulação de conceitos pop. Imagem símbolo: uma antena parabólica enfiada na lama (G1, 2009).

A antena parabólica enfiada na lama é a imagem que representa a conexão entre a capacidade de união entre a rede mundial de circulação de informação, à disposição dos indivíduos graças aos avanços tecnológicos das últimas décadas e o ecossistema costeiro do mangue, biodiverso, também ele repleto de informações e possibilidades a partir da própria natureza. Fincada na lama do mangue, no chão do Recife, é possível a antena se conectar ao mundo e a proliferação de signos do mundo pop.

Hoje, os mangueboys e manguegirls são indivíduos interessados em hip-hop, colapso da modernidade, caos, ataques de predadores marítimos (principalmente tubarões), moda, Jackson do Pandeiro, Josué de Castro, rádio, sexo não-virtual, sabotagem, música de rua, conflitos étnicos, midiotia, Malcom Maclaren, Os Simpsons e todos os avanços da química aplicados no terreno da alteração e expansão da consciência (Idem).

A lista, nos parece, poderia prosseguir indefinidamente; à maneira pós-moderna, enfeixa uma incomensurabilidade de informações à disposição de qualquer indivíduo, por mais miserável que possa ser sua condição econômica. É essa enxurrada de informações que tira a juventude recifense do marasmo que estava por décadas, submetida à violência, à fome e à miséria. De uma maneira que poderíamos dizer também pós-colonial, a partir das margens, constrói-se uma tentativa de lançar-se no mundo e apresentar uma visão que tenta dar conta da totalidade do capitalismo tardio, mesmo que ao final a empreitada termine em fracasso, visto que esta totalidade é incomensurável. Mas há de forma perceptível aquilo que identificamos como o esmaecimento da história enquanto um dos sintomas do pós-modernismo. A listagem coloca em pé de igualdade o geógafo Josué de Castro, referência fundamental no debate sobre a desigualdade no Brasil, e ataques de tubarões e drogas lisérgicas. É a admissão de que o mapa de um mundo caótico só pode se constituir ele também a partir de uma colagem esquizofrênica e provisória.

\section{O ciberespaço como forma de representar a totalidade}

Um outro exemplo deste mapeamento cognitivo, dentre inúmeros que poderíamos colher das análises 
e críticas feitas por Jameson, pode ser encontrado em sua investigação sobre o gênero (ou sub-gênero). do cyberpunk. Ele identifica no cyberpunk uma forma que lida com a corrosão do que entendíamos como a "Sociedade civil".

$\mathrm{O}$ autor pensa o gênero Cyberpunk ao lado daquilo que ele chama de Realismo Sujo, de maneira aproximada ao que foi o Naturalismo Francês do Século XIX, com sua forma consagrada nos romances de Emile Zola. O Cyberpunk é um outro tipo de naturalismo, um no qual desaparece justamente a noção de alteridade tão cara aos romances do Século XIX.

Em Zola e em outros atores, o que se faz é um retrato das "classes perigosas" para o agrado e entretenimento de um público burguês, uma representação de ansiedades da época, o medo de uma classe elevada de decair às condições de vida mais pobres e degradantes. Essa distinção morre no Cyberpunk (JAMESON, 1997a, p.153). Há, na verdade, uma circularidade entre os espaços baixos e altos da cidade. Um empresário decadente pode se reerguer da sarjeta. Um punk pode hoje estar no alto escalão corporativo e amanhã nos becos e vielas drogando-se e batendo carteiras, ou o contrário.

Tal circulação é representativa, seguindo o raciocínio de Jameson, de um esmaecimento da dicotomia entre o público e o privado que é própria da pós-modernidade, a erosão daquilo que foi conhecido como sociedade civil. Em seu lugar, emergem espaços de ninguém, entendidos como regiões que não possuem uma identidade clara, uma configuração precisa no espaço, uma demarcação territorial firme. Esses locais parecem-se se mais genéricos que se repetem em diferentes regiões do mundo uniformemente: locais de trabalho, espaços da rua, ou mesmo alguns que parecem estar acima da lei, sem nenhuma jurisdição clara (Idem, p. 164). O Cyberpunk teoriza sobre o que vem depois da sociedade civil, o que a substitui (Idem, 162). Agora, até o governo se torna privado: no mundo Cyberpunk imperam as megacorporações e grupos criminosos, milícias etc (Idem, p. 164).

Pensando o caso paradigmático do gênero, o romance Neuromancer, de William Gibson (2016), Jameson analisa como há um trabalho cooperativo envolvido na trama, o que pode ser visto como o traço de uma utopia. Lembremos que na história do romance é proposto o roubo, ou resgate, de um conjunto de dados de uma megaempresa. Para isso devem se unir pessoas com distintas habilidades, um hacker, uma garota guerreira com lâminas de aço, um homem responsável pelo transporte etc. Essa organização cooperativa indica um tipo de aliança, uma coletividade.

Mas, o mais importante é que para o autor o ciberespaço no romance se configura como uma alegoria para aquilo que é quase irrepresentável, o fluxo de capitais e informações no capitalismo tardio, em especial o próprio capital financeiro. Assim como as finanças globais, no ciberespaço os personagens também se movem em larga velocidade e percorrem continentes em pouquíssimo tempo. De fato, hoje, em uma sociedade cada vez mais determinada por algoritmos e pelo chamado big data, o romance de Gibson não parece premonitório, mas uma verdadeira proposta estética e organizativa para o que veio depois na indústria.

O ciberespaço é, nessa leitura, uma forma do romance lidar com transformações da realidade capitalista, e também de representar, ou mapear a totalidade no que ela tem justamente de irrepresentável, de impossível, o incomensurável do fluxo global de finanças e informações. Uma plenitude que se relaciona de forma conflitiva com o local, o pequeno espaço onde os personagens também se movem.

Ao mesmo tempo, um outro recurso utilizado pelos personagens do livro é o chamado "simstim". Por meio dele, conseguem fazer um procedimento de entrar no corpo de um outro, ver com seus olhos, acompanhar seus movimentos, pertencer a este pequeno espaço que é o próprio corpo de outro sujeito. O romance então apresenta duas experiências: tanto a do grande fluxo global de informações, quanto a visualização do mundo a partir dos olhos de uma pessoa, de um outro corpo em sua mínima localização.

Essa dialética entre local e global ${ }^{1}$ é parte da forma do romance Neuromancer e também uma maneira de lidar com uma contradição que de alguma forma todos nós estamos envolvidos no capitalismo globalizado. A obra consegue, portanto, interseccionar a experiência individual, diríamos até psicológica, com o conhecimento derivado da ciência, da economia, da sociologia ou de outras grandes áreas de conhecimento que não conseguimos perceber diariamente. Faz-se uma conexão entre subjetivo e objetivo dentro da forma artística.

Pensamos que recorrer ao exemplo do cyberpunk é produtivo também por nos colocar em contato com a figura do cyborg, o indivíduo que não é humano, nem tampouco máquina, mas um híbrido. Uma figura comum no universo de Neuromancer e que tem sido recorrentemente teorizada por sua possibilidade de superação das barreiras naturais e ao mesmo tempo humanas, dentro daquilo que pode ser chamado de pós-humanismo. Fica a dúvida se este ser pode abrir um novo caminho para o que entendemos como sujeito, ou mesmo sua superação, ou é apenas a representação da definitiva colonização de todo o mundo

\footnotetext{
Por dialética entre global e local nos referimos ao conflito entre o movimento dos personagens no romance a partir de seu próprio corpo, dentro do que seria o "real" e a movimentação dentro do ciberespaço, uma alegoria pra rede de circulação enorme de informações no capitalismo tardio. A interação no romance entre essas duas formas de circulação corpo/informações no ciberespaço dá o tom dessa dialética entre local e global.
} 
vivente pelo capital, sendo o corpo humano a última barreira biológica e vital a ser conquistada pela lógica das mercadorias.

Um último exemplo, de proporções maiores e que exigiria mais investigação, se dá na referência de Jameson à câmera. Aqui, seguindo autores como Virilio e Cavell, ele sugere que a câmera cinematográfica serve como um sujeito sem subjetividade, o resultado final de todo o debate pós-moderno sobre o descentramento do sujeito. Em uma linha de raciocínio que nos recorda do cine-olho de Dziga Vertov (2018, p.211), a câmera é vista como uma emancipação do olho humano em direção ao aparato, que é uma máquina vazia, descentrada e capaz de registrar o cotidiano de múltiplas perspectivas, a busca por um registro de infinitos espaços e temporalidades:

Mas a modernidade de fato inventou um hiperespaço do qual se observa o observador: é a chamada câmera. E o filme se torna a extensão lógica da narrativa de viagem no tempo, naquele sentido paradoxal de que, como Stanley Cavell colocou de forma tão memorável, o mundo é visto sem mim mesmo. É isto, então, onde a busca estrutural/pós-estrutural por um sujeito descentrado terminou, não com alguma impossível "morte do sujeito", mas ao invés na film theory, com o aparato da câmera como o último sujeito sem subjetividade, aquela última encarnação visual e literal do último observador do último eu e da literalização do "ponto de vista" literário de James. O hiperespaço transcendental no qual tal observador transcendental encontra a si mesmo é então o regresso infinito do ponto de vista, o vazio no qual a tentativa de se pensar o tempo e a temporalidade, de se pensar o passado e o presente, de se pensar a diferença entre meus múltiplos eus é encontrada. Temporalidade então não é nada além de uma narrativa de viagem no tempo (JAMESON, 2015b, nossa tradução). ${ }^{2}$

Além disso, a desaparição daquele sujeito burguês cartesiano, centrado na tradição filosófica europeia pode ser vista de uma maneira mais positiva como a entrada em cena de outros sujeitos, justamente aqueles povos explorados nas colônias da Ásia, África, América e Oceania. Povos a quem não eram concedidos os direitos

\footnotetext{
2 "But modernity has in fact invented such a hyperspace from which to observe the observer: it is called the camera. And film becomes the logical extension of the time-travel narrative in that paradoxical sense in which, as Stanley Cavell so memorably put it, the world is viewed without myself. This is, then, how the structural/poststructural search for the decentred subject ended up, not with some impossible 'death of the subject', but rather in film theory, with the camera apparatus as that ultimate subject without subjectivity, that ultimate literal and visual embodiment of the ultimate observer of the ultimate self and of the literalisation of James's literary 'point of view'. The transcendental hyperspace in which such a transcendental observer finds itself is then simply the infinite regress of point of view, the nothingness on which the attempt to think time and temporality, to think the past and the present, to think the difference between my multiple selves, is founded. Temporality is then nothing but a time-travel narrative" (JAMESON, 2015b).
}

básicos da modernidade. A existência deles ultrapassa os limites da população branca europeia e abre espaço para outras sensibilidades temporais e principalmente espaciais:

Não mais protegidas pela família ou pela região, nem sequer pela própria nação e sua identidade nacional, a emergência do sujeito vulnerável em um mundo de bilhões de equivalentes anônimos é um salto para trazer mais mudanças importantes na realidade humana. A experiência da singularidade é, nesse nível, a verdadeira expressão dessa destituição subjetiva, constantemente remediada pela regressão em grupos mais velhos de estruturas religiosas, ou a invenção das identidades étnicas pseudo-tradicionais, com resultados variando do genocídio aos hobbies luxuriosos (JAMESON, 2015a, p. 130). ${ }^{3}$

Pode-se dizer então que além do velho sujeito burguês e do novo sujeito esquizofrênico pós-moderno temos um terceiro, um sujeito coletivo, não-centrado, parte de um grupo-orgânico (JAMESON, 1997, p. 346).

\section{Conclusão}

Ao final desse artigo, pensamos ter deixado claro porque acreditamos que Fredric Jameson fornece um panorama interessante sobre o pós-modernismo que pode nos auxiliar a pensar a cultura e a arte no século XXI. Há outros autores que debatem sobre o pós-modernismo e a pós-modernidade, mas Jameson, ao entender a pósmodernidade como um estágio do capitalismo, que também chama de capitalismo tardio, e o pós-modernismo como sua dominante cultural, abre caminho para uma compreensão mais ampla e histórica da situação, mesmo que a história apareça com novos sintomas: a nostalgia, o pastiche das velhas formas, a espacialização do tempo e o esmaecimento do afeto.

Adotar a categoria da totalidade, mesmo em um momento em que esta foi tão posta em questão, também traz alguns problemas interessantes, na medida em que desafia o crítico a entender o que é esta totalidade e suas possibilidades de representação, ou suas impossibilidades, em formas contemporâneas.

Observar a totalidade do capitalismo para pensar a cultura também nos permite inserir a reflexão sobre os novos movimentos sociais e questões políticas que ganharam mais evidência a partir dos anos 1960. Mais

\footnotetext{
3 "No longer protected by family or region, nor even by the nation itself and its national identity, the emergence of the vulnerable subject into a world of billions of anonymous equals is bound to bring about still more momentous changes in human reality. The experience of singularity is, on this level, the very expression of this subjective destitution, one so often remedied by the regression into older group or religious structures, or the invention of pseudo-traditional ethnic identities, with results ranging from genocide to luxury hobbies" (JAMESON, 2015, p. 130)
} 
do que suprimir as contradições de classe, pensamos que as questões feminista, indígena, LGBT, decolonial, negra, estudantil e tantas outras contribuem para uma atualização da nossa compreensão do mundo.

Se a concepção cartesiana e burguesa de sujeito é desafiada, pensamos que isto deve ser encarado como uma forma de repensar a definição do humano. É aí que o mapeamento cognitivo aparece para nós como um procedimento importante, tanto de representação estética quanto de inserção política. Pensamos que é um procedimento que pode render frutos no sentido de lidar com o descentramento do sujeito produzido pelas transformações do capitalismo.

\section{Referências}

DOCTOROW, E. L. Ragtime. Rio de Janeiro: Record, 2017.

FLISFEDER, Matthew. Postmodern Theory and Blade Runner. London/New York: Bloomsbury Academic, 2017. https://doi.org/10.5040/9781501311789

GIBSON, William. Neuromancer. São Paulo: Aleph, 2016.

JAMESON, Fredric. Aesthetics of singularity. New Left Review, London, v. 92, p. 101-132, mar./abr. 2015a.

JAMESON, Fredric. As sementes do tempo. São Paulo: Ática, 1997a.

JAMESON, Fredric. In Hyperspace. London Review of books, London, v. 37, n. 17, p. 17-22, set. 2015b.

JAMESON, Fredric. Modernidade Singular. Rio de Janeiro: Civilização brasileira, 2005.

JAMESON, Fredric. $O$ inconsciente politico: A narrativa como ato socialmente simbólico. São Paulo: Ática, 1992.

JAMESON, Fredric. Pós-modernismo: A lógica cultural do capitalismo tardio. São Paulo: Ática, 1997b. https://doi.org/ 10.11606/d.8.2013.tde-12022014-113107

JAMESON, Fredric. The Geopolitical Aesthetic: Cinema and Space in the World System. Lonres: Bfi Publishing, 1995.

LEIA o manifesto 'Caranguejos com cérebro'. G1, São Paulo, 18 set. 2009. Disponível em: http://g1.globo.com/noticias/ musica/0,,mul1308779-7085,00-leia +o+manifesto+caranguejo $\mathrm{s}+$ com + cerebro.html

PEREC, Georges. A vida: modo de usar. São Paulo: Companhia das Letras, 1991.

PERONE-MOISÉS, Leyla. Mutações da Literatura no século XXI. São Paulo: Companhia das Letras, 2015. https://doi. org/10.4067/s0718-22952018000200400
VERTOV, Dziga. Nascimento do Cine-Olho. In: XAVIER, Ismail (org.). A experiência do Cinema (Antologia). São Paulo: Paz \& Terra, 2018. p. 211-213.

Recebido: 07/1/2019

Aceite: 29/10/2019

Publicado em: 21/12/1019.

Autor:

WIBSSON RIBEIRO LOPES

Graduação e Mestrado em História na Universidade Federal de Alagoas. Doutorando no Instituto de Estudos da Linguagem da Universidade Estadual de Campinas (IEL/UNICAMP), Campinas, SP, Brasil. Orcid: https://orcid.org/0000-0001-8047-6460

E-mail:wibsson@gmail.com

Endereço: Cidade Universitária Zeferino Vaz - Barão Geraldo 13083-970, Campinas, SP, Brasil 